\title{
LA MORAL COMO FORMA DEFICIENTE DE DERECHO
}

\section{1. ¿Un resto de metafísica en el derecho positivo?}

abido es que en estos tiempos «post» que corren no es precisamente el afán sistemático el que preside las reflexiones filosóficas. Pero también es verdad que algunas de ellas se presentan como propuestas teóricas que pueden trabajarse radialmente en distintas direcciones. Este es, sin duda, el caso de la oferta habermasiana, que hace su entrada en el mundo cultural con haberes tales como la pragmática universal, la teoría de la acción comunicativa, una nueva teoría de la racionalidad, una teoría consensual de la verdad, una teoría de la evolución social y una ética discursiva. En este denso contexto teórico-práctico de elaboraciones radiales una preocupación ha ido destacándose en los últimos tiempos: examinar las complejas relaciones existentes entre derecho, moral y eticidad, realizar un seguimiento crítico del debate sobre la juridificación y analizar las conexiones que, al hilo de todo ello, se desvelan entre una ética postconvencional de principios, un derecho positivo que se sabe necesitado de fundamentación, y la idea de un estado de derecho, que tiene por canon crítico la idea de imparcialidad ${ }^{1}$ : la conexión, en suma, entre un tipo de moral, de derecho y de política, que responde con sus peculiares matices a la estructura de la racionalidad práctica, descubierta a través del núcleo teórico-práctico al que antes hemos aludido ${ }^{2}$.

${ }^{1}$ J. Habermas, «Entgegnung», en a. Honneth/H. Joas (Hg.), Kommunikatives Handeln, Frankfurt, Suhrkamp, 1986, pág. 327.

${ }^{2}$ J. Habermas, «Moral und Sittlichkeit. Hegels Kantkritik im Lichte der Diskursethik», en Merkur, H. 442 (1985), 1041 ss.; «Moralität und Sittlichkeit. Treffen Hegels Einwände gegen Kant auch auf die Diskursethik zu?», en W. Kuhlmann (Hg.), Moralität und Sittlichkeit, Frankfurt, Suhrakmp, 1986, 16-37; «Recht und Moral, Zwei Vorlesungen», manuscrito inédito; «Wie ist Legitimität durch Legalität möglich?», en Kritische Justiz, Jg. 20, H. 1 (1987), 1-16. Yo misma me he ocupado de las relaciones entre moral, derecho y política en la ética discursiva en «El ethos democrático: entre la anarquía y el Leviatán», en Sociedad civil y Estado, Fundación F. Ebert e Instituto Fe y Secularidad, Salamanca, 1988, 85-97; «Límites y virtualidades del procedimentalismo moral y jurídico», en Anales de la 
La tesis central de nuestro autor con respecto a la estructura del ámbito práctico consistirá en defender que moral postconvencional, derecho positivo y estado democrático son ciertamente tres ámbitos diferentes en el espectro práctico, pero que a la vez resultan inseparables, no sólo por complementarios, sino también por hallarse inevitablemente entrelazados. Una moral postconvencional de la responsabilidad precisa complementación jurídica, porque no puede exigir responsablemente el cumplimiento de las normas válidas si los destinatarios no tienen garantía jurídica de que serán universalmente cumplidas ${ }^{3}$; pero igualmente el derecho positivo, deficitario desde el punto de vista de la fundamentación, precisa el concurso de una razón moral, que expresa en su seno la idea de imparcialidad procedimental. En lo que a la idea de estado de derecho se refiere, y aun cuando la política sea el ámbito propio del pacto y la negociación, no es menos cierto que la legitimidad política hunde sus raíces en una legalidad que refleja la estructura de la razón práctica; pero, por otra parte, también la fuerza legitimadora del derecho tiene su fuente en el proceder democrático legislador. Y es que una reconstrucción del surgimiento y evolución de cada una de las dimensiones del ámbito práctico, a partir de un núcleo primitivo indiferenciado, muestra su entrelazamiento en la medida en que cada uno de ellos se encuentra condicionado y es condición de la evolución de los restantes.

Mantener tales tesis supone obviamente enfrentarse a la teoría weberiana de la racionalización que, aplicada al derecho moderno, llegará a afirmar que la legitimidad de los órdenes políticos modernos sólo es posible por la legalidad, en la medida en que ésta posee determinadas cualidades formales en las que se expresa su específica racionalidad. Es menester, pues, revisar, no sólo la concepción weberiana del derecho, sino también su concepción de la racionalidad.

En efecto, bajo la perspectiva weberiana la fuerza legitimadora del derecho no procede de su conexión con la moral, sino todo lo contrario: cualquier intento de moralización -de introducción de postulados tales como «justicia» o «dignidad humana»supone un intento de materializar el derecho, destruyendo su racionalidad formal. $\mathrm{Y}$, sin embargo, a partir del análisis weberiano

Cátedra Francisco Suárez, núm. 28 (1988), 43-63; «Pragmática formal y derechos humanos», Tanner-Lectures, en prensa.

${ }^{3}$ Esta sería, a mi juicio, una de las razones que abonaría la obediencia al derecho, si es que queremos resucitar la polémica suscitada entre nosotros por F. González Vicén y en la que, por lo que sé, han intervenido E. Díaz, J. Muguerza, M. Atienza, E. Fernández, E. Gisán y en la que yo misma me he permitido participar. 
de la formalización del derecho se desvelan supuestos en él implícitos de teoría moral, que resultan inconciliables con la neutralidad axiológica, declarada por Weber al respecto. Únicamente entendiendo la racionalidad en un sentido moralmente neutral, tiene consistencia la prevención de Weber contra la introducción de la justicia en el derecho positivo: aceptando la racionalidad como racionalidad de reglas, racionalidad de la elección y racionalidad científica, las cualidades formales del derecho sólo pueden describirse como racionales en un sentido moralmente neutral ${ }^{4}$. Sin embargo, ¿son estos aspectos los que prestan fuerza legitimadora a la legalidad de la dominación o esta tarea viene realizada por implicaciones morales que pueden extraerse de ellos, con ayuda de supuestos empíricos sobre la constitución y el funcionamiento del orden económico?

Valores como la seguridad jurídica, la igualdad ante la ley, la posibilidad de someter los principios jurídicos a una prueba discursiva, prestan fuerza legitimadora a una racionalidad formal, que no es en modo alguno moralmente neutral. El «error» de Weber consistiría, entre otros, en considerar la esfera del derecho como un orden que, como la economía y el estado, es susceptible de racionalización en el sentido de la racionalidad teleológica, obviando el aspecto fundamentador de la razón práctico-moral, para limitarse al aspecto cognitivo-instrumental de aplicación ${ }^{5}$. Sin embargo, el derecho que conocemos ha heredado dos momentos que acuñaban el sistema jurídico en las antiguas culturas -su carácter de no disponible y, sin embargo, a la vez de instrumentalizable-, que no quedan recogidos en esa noción de derecho positivo, sometido a los cánones de la razón teleológica.

En efecto, una reconstrucción del surgimiento del derecho moderno nos muestra cómo en la estructura jurídica trimembre de las antiguas culturas -configurada por el derecho sagrado, el derecho burocrático del soberano y el derecho consuetudinario- se alojan dos momentos, de los que más tarde tratarán de dar cuenta el derecho racional y el positivo: el soberano está subordinado a un derecho sagrado que le presta legitimidad y que, por tanto, es para él intocable y, por otra parte, se sirve del derecho instrumentalmente al regular judicialmente los conflictos. La pérdida de las imágenes del mundo con contenido y la

${ }^{4}$ J. Habermas, Theorie des Kommunikativen Handelns, Franfurt, Suhrkamp, 1981, I, 239 ss. (=TkH); «Wie ist Legitimität durch Legalität möglich?» (Erste Vorlesung über Recht und Moral).

${ }^{5}$ J. Habermas, TkH, I, 332 ss. 
absorción del derecho consuetudinario en el derecho de los expertos, conllevan la destrucción de la estructura trimembre del derecho y su reducción a un derecho positivo, que debe seguir ostentando los dos antiguos caracteres: intocabilidad e instrumentalidad. El primer intento de mantener la síntesis corre a cargo del derecho racional.

En el derecho racional moderno un nivel postradicional de la conciencia moral hace depender el derecho de principios y transforma su racionalidad en racionalidad procedimental. A pesar del descuido weberiano del formalismo ético y de las teorías contractuales en este punto, precisamente el contractualismo trata de conectar los dos momentos aludidos, aunque sin éxito, porque si una línea como la hobbesiana garantiza la instrumentalidad del derecho positivo, pero no su «indisponibilidad» por parte del soberano, una línea como la kantiana asegura su intocabilidad, pero no su carácter instrumental. Ciertamente, no es posible fundamentar en el pacto mismo la fuerza del derecho, porque la obligatoriedad categórica que acompaña al principio «pacta sunt servanda» subyace al pacto. $\mathrm{Y}$ es este nivel categórico de fundamentación, trasunto del derecho sagrado, el que queda satisfecho en la fundamentación moral del derecho kantiano -y no en el instrumentalismo hobbesiano-, si bien al precio de convertir al derecho en un modo deficiente de la moral.

Sin embargo, a pesar del fracaso del derecho racional, es menester extraer útiles enseñanzas tanto del formalismo ético como de la figura jurídico-política del contrato social: el formalismo ético limita su tarea a proporcionar un test para comprobar la validez de las normas morales, dejando al margen las preferencias axiológicas, aconsejables en un ethos concreto; mientras que la figura del contrato propone un procedimiento cuya racionalidad garantiza la corrección de las decisiones tomadas desde él. Esta es, precisamente, la oferta que debe aceptar un derecho positivo contemporáneo, consciente del carácter irreversible del impulso de la juridificación y que no quiera retornar al iusnaturalismo o al «materialismo» ético.

En efecto, el análisis habermasiano del impulso de la juridificación, propio del estado social, le lleva a concluir que está ligado a una moralización del derecho y que el proceso es irreversible. Se trata, pues, de buscar un fundamento moral del derecho, que no reviva las propuestas del derecho natural -sea desde el cristianismo, sea desde la ética de los valores- ni regrese tampoco a Aristóteles, porque ni uno ni otro son apropiados para destacar el núcleo racional de la praxis judicial. En la disputa entre procedimentalistas y sustancialistas sólo los primeros pueden 
suplir el déficit de fundamentación del derecho positivo, porque la aceptación de cualquier contenido imposibilitaría el universalismo normativo, necesario en una sociedad pluralista. Y ésta es, a mi juicio, la gran «verdad» del procedimentalismo: que puede pertrecharnos de los elementos morales necesarios, porque la carencia de contenidos y la opción por el procedimiento alumbran obligatoriedad universal en un contexto pluralista ${ }^{6}$.

Calificar de iusnaturalista esta posición parece, pues, improcedente, trátese de un iusnaturalismo ontológico o deontológico, desde el momento en que no distinguimos entre dos tipos de derecho -natural y positivo-, ni deducimos principios jurídicos de un concepto de naturaleza humana, ni trazamos principios jurídicos que legitimen el derecho positivo, ni negamos tampoco carácter de derecho a un sistema normativo, reconocido por órganos que tienen acceso al aparato coactivo estatal, por el hecho de que no satisfagan principios de justicia ${ }^{7}$. Sin embargo, tales principios están entrañados en el seno mismo del derecho positivo, como condición de sus cualidades procedimentales: contravenirlos supone privar al derecho de su marco legitimador y también a la organización política que recibe su legitimidad de tal legalidad.

Porque el carácter categórico, sin el que el derecho positivo carece de una fuerza obligante que trasciende los pactos, y que tuvo sus raíces en el derecho sagrado, pasando después a constituir el núcleo del derecho racional, se desplaza ahora al interior del derecho positivo mismo: las normas jurídicas, dado que a ellas subyace una pretensión de corrección, no expresan sólo una racionalidad cognitivo-instrumental, sino también una racionalidad comunicativa. En el derecho positivo leemos un momento moral -su momento fundamentador- que consiste en «la fuerza trascendente de un procedimiento autorregulador, que controla su propia racionalidad».

Se trata, pues, de contraer la doctrina kantiana de los dos mundos, como es usual en el proceder habermasiano, convirtiendo

\footnotetext{
${ }^{6}$ La imposibilidad de conectar pluralismo y iusnaturalismo absolutista es destacada por N. López Calera en su Introducción al Estudio del Derecho, Granada, Don Quijote, 1981, 152 y 153.

${ }^{7}$ Un iusnaturalismo del primer tipo sería defendido, entre otros, por J. Ballesteros, en Sobre el sentido del Derecho, Madrid, 1984; mientras que A. E. Pérez Luño se pronuncia por un iusnaturalismo deontológico (Derechos humanos, estado de derecho y constitución, Madrid, Tecnos, 1984, 137). La última caracterización de iusnaturalismo que aparece en nuestro texto está tomada de C. S. Nino, Ética $y$ derechos humanos, Buenos Aires, Paidós, 1984, 24 y 25.
} 
la doble perspectiva en dos momentos en tensión de un mismo ámbito. Si frente al contextualismo radical es preciso defender un mínimo de racionalidad universal, es porque ésta se revela como a la vez inmanente y trascendente a la praxis cotidiana. Inmanente, porque no puede expresarse más allá de los juegos lingüísticos concretos, de los contextos en que los individuos se pronuncian por el sí o por el no; trascedente porque las pretensiones de validez del habla trascienden en su exigencia universal los límites contextuales de la praxis determinada. Un «resto de metafísica» queda, pues, en este carácter trascendente, categórico, de la racionalidad comunicativa: el resto de metafísica necesario para combatir a la metafísica, pero que debería impedir a Habermas llamar a nuestro tiempo «postmetafísico»; precisamente porque es este resto el que dota de sentido, de un canon normativo y crítico ${ }^{8}$.

Y esto mismo puede decirse del mundo jurídico, porque mientras no esté únicamente en manos de la racionalidad cognitivo-instrumental, sino que dependa de la pretensión de corrección normativa, muestra su núcleo una racionalidad a la par inmanente y trascendente, que contrae en el derecho positivo la doble perspectiva del idealismo trascendental: la instrumentalidad de los imperativos propios de la perspectiva fenoménica y la categoricidad de las leyes morales, propias de la perspectiva nouménica, que Kant aún distribuía en el mundo jurídico entre el derecho positivo y el racional, se contraen en el derecho positivo.

No es menester, pues, ir más allá del derecho positivo buscando una fundamentación iusnaturalista, ni siquiera una fundamentación ética en el concepto de dignidad humana ${ }^{9}$; pero tampoco podemos conformarnos con la plena inmanencia de un positivismo craso, porque el momento trascendente -el momento normativo de la tradición sagrada- forma parte constitutiva del derecho positivo.

Contamos -dirá Habermas- con teorías de la justicia construidas procedimentalmente que, situadas en la tradición kantiana,

${ }^{8}$ Esta es una de las críticas dirigidas por J. Conill a J. Habermas, en diálogo con uno de los trabajos de Habermas que más tarde aparecería en Nachmetaphysisches Denken, Frankfurt, Suhrkamp, 1988. Vid. J, Conill, El crepúsculo de la Metafísica, Barcelona, Anthropos, 331.

${ }^{9}$ Esta sería la posición de E. Fernández en Teoría de la justicia y derechos humanos, Madrid, Debate, 1984, 104 ss., en referencia concreta al tema de los derechos humanos. G. Peces-Barba critica tal posición y las reseñadas en nota 7, defendiendo a la par su postura «realista» en Escritos sobre derechos fundamentales, Madrid, Eudema, 1988. 
prestan mayor credibilidad al punto de vista defendido: el neocontractualismo rawlsiano, «decisionista» en exceso, al parecer de Habermas: la kohlbergiana teoría del desarrollo de la conciencia moral, asaz «empática» al gusto habermasiano por servirse de la asunción de rol, y la ética discursiva, que se siente más próxima a Kant por pertrecharnos de un proceder argumentativo en la formación racional de la voluntad, pero supera a Kant por cuanto la universalidad propuesta es procedimental y no meramente formal ${ }^{10}$.

Podemos decir, pues, que la legitimidad es posible por la legalidad porque un resto de metafisica -del que tanto Habermas como Rawls abjuran abiertamente- anida en el concepto de racionalidad y, consecuentemente, en el derecho autónomo. Pero, por otra parte, si hacer del derecho un modo deficiente de la moral atenta contra su autonomía, también cabe preguntar si las éticas de tradición kantiana no han tendido más bien a hacer de la moral una forma peculiar -cuando no deficiente- de derecho. Buscar el origen de tal tendencia en la filosofía práctica kantiana tal vez no resulte desatinado, aunque sea el proceso de des-subjetivación sufrido a partir de ella el que está situando a la moral en un no-lugar. El paso a la filosofía del lenguaje a través de la psicología social de G. H. Mead no se ha producido sin consecuencias.

\section{Reino de los fines y paz perpetua}

Que la filosofía kantiana en su totalidad pueda interpretarse desde la perspectiva de una filosofía jurídica es una hipótesis plausible desde el momento en que la deducción trascendental es

${ }^{10}$ Siguiendo una línea interpretativa que ha dado en ser semejante, intenté en un trabajo, publicado en esta misma revista, extraer de la «justicia como imparcialidad» elementos para una fundamentación moral del derecho («La justificación ética del derecho como tarea prioritaria de la filosofía política. Una discusión desde John Rawls», en Doxa, núm. 2 [1985], 129-144). Mantenía allí -y ahora- que una filosofía política que pretende articular adecuadamente libertad e igualdad para un modelo político democrático -modelo que se legitima legalmente- requiere como tarea prioritaria una reflexión moral sobre los fundamentos del derecho. En este sentido, la justicia como imparcialidad nos pertrecharía de un iusnaturalismo y personalismo procedimentales, basados en la procedimentalización de la noción moral kantiana de persona, por tanto, en la autonomía, y que permiten una justificación empírico-práctica. Una de sus mayores limitaciones consistiría en intentar conectar normatividad y relativismo contextualista (en el sentido etnocéntrico señalado por R. Rorty, vid. nota 22 de este trabajo). 
una prueba de la posesión de determinados conocimientos. Aunque las Preguntas «quid juris?» y «quid sit ius?» no se identifican, el reto de la razón práctica «no debe haber guerra, porque éste no es el modo en que los hombres se procuran su derecho» no se dirige únicamente a los individuos o a los estados entre sí en estado de naturaleza, sino también a cuantos disputan acerca de la legitimidad de los presuntos conocimientos de la razón. De ahí que en alguna ocasión me haya permitido calificar a la razón crítica de razón jurídica ${ }^{11}$.

Pero, a mayor abundamiento, tanto la esfera de la naturaleza como la de la libertad son posibles por una idea central: la idea de ley, proceda del entendimiento para el conocimiento teórico de la naturaleza, proceda de la razón para actuar bajo la idea de libertad. Y aunque por ello se haya acusado a Kant de incurrir en falacia naturalista, al convertir a la ley natural en falsilla de la ley moral, también cabe preguntar si en último término no incurre en falacia humanista, porque tal vez el mundo natural haya «aprendido» legalidad del mundo humano. ¿Surge este concepto de ley de la experiencia religiosa, de la experiencia moral o de la experiencia jurídica?

Ciertamente en la tradición occidental la experiencia moral es más la de la virtud como excelencia del carácter y la de la felicidad como búsqueda de la vida buena ${ }^{12}$. Será la Stoa quien dote a la moral de un sello deontológico tras la quiebra de la polis y la Edad Media quien haga confluir felicidad y cumplimiento de la ley divina, pero el concepto de ley es más propio originariamente del mundo jurídico-político que del moral. La subjetivación de la felicidad y de los fines acaba situando a la ley en el centro de la reflexión moral en las filosofías de tradición kantiana, pero todavía en la del iniciador de ellas existen criterios para distinguir entre una moral y un derecho unidos por la idea de ley: mas queda la moral «juridificada» que el derecho «moralizado», porque la categoricidad del derecho racional no por eso le convierte en moral.

Criterios distintivos entre ambos tipos de legislación serían, entre otros, los siguientes: 1) el móvil del agente -en el primer caso el respeto a la ley, en el segundo, un móvil empírico; 2) el tipo de coacción -autocoacción en lo que respecta a la moral, coacción externa en cuanto al derecho, 3 ) el ámbito de libertad

${ }^{11}$ A. Cortina, Estudio Preliminar a I. Kant, La metafísica de las costumbres, Madrid, Tecnos, 1989, XV-XCI, especialmente XXIII-XXXI. Kant mismo hablará de «una razón superior y judicial» en $\mathrm{KrV}$, A 739 B 767.

${ }^{12}$ J. Montoya-J. Conill, Aristóteles: sabiduría y felicidad, Madrid, 126 ss. 
-interna o externa- regulada; 4) los objetos de la legislación -las máximas en el caso de la moral, las acciones en el del derecho; 5) el tipo de exigencia -moralidad o sólo legalidadque cada una de estas legislaciones puede plantear al agente; 6) el sujeto que juzga acerca de la legitimidad de la norma -el sujeto agente o el legislador; 7) el ideal al que la legislación se dirige, que en el caso de la moral consiste en una comunidad ética, un reino de los fines, para acceder al cual se precisa una conversión personal del corazón, mientras que un derecho «situado dentro de los límites de la mera razón» tiende a una paz perpetua por la que trabajaría hasta un pueblo de demonios como seres inteligentes ${ }^{13}$.

Ciertamente, asignar al sujeto un ámbito de libertad interna, hacer de ella el fundamento de lo moral y considerar al sujeto autónomo como criterio último de la corrección del juicio moral, supone conceder al formalismo moral un status propio frente a la legislación religiosa y jurídica: al sujeto autónomo queda decidir si una máxima es ley moral y es la conversión del corazón la que lleva a un reino de los fines. Mientras que el derecho racional está acuñado por la categoricidad, pero no por la moralidad: el principio de la autonomía de la voluntad no se identifica con la voluntad unida del pueblo, ni el juicio del sujeto autónomo es el del legislador jurídico, ni es la conversión del corazón la que lleva a un pueblo de demonios a trabajar por una paz perpetua. El veto de la razón práctico-moral «no debe haber guerra» tiene también por destinataria a la razón prudencial y hábil, porque el imperio de la legalidad no es ya el de la moralidad.

\section{3. ¿Núcleo moral o derecho racional?}

El tránsito del formalismo al procedimentalismo, de la lógica trascendental a la pragmática universal o trascendental, no se produce sin repercusiones para el sujeto autónomo y, por tanto, para el «punto de vista moral». Jirones sustantivos suyos han quedado por el camino, como es el caso del móvil moral, el ámbito de la libertad interna, la autocoacción, el tipo de exigencia, el sujeto del juicio moral, incluso el ideal de la legislación moral, porque todo lo que apunta a una «dimensión interior» se ha ido borrando del horizonte. En el contexto de la ética discursiva la moral se concibe ahora -igual que el derecho- como un mecanismo

${ }^{13}$ I. Kant, Zum ewigen Frieden, VIII, 366; MdS, VI, 354 y 355. 
de resolución de conflictos, aunque las normas morales -se dice- son fin en sí, mientras que las jurídicas son también medios para metas políticas. Ciertamente, los conflictos morales pueden presentarse a la deliberación individual y no sólo a la social, pero en tal caso más se trata de una internalización porque, negado por falaz el solipsismo metódico, nos acogemos a Hegel y a la psicología social de G. H. Mead. «Somos los que somos -repetirá Habermas, recordando a Mead- gracias a nuestra relación con otros»; la universalidad moral hunde sus raíces en la socialidad y por ello es menester universalizar, no sólo la forma, sino también el contenido del acto: es menester universalizar los intereses ${ }^{14}$.

En este proceder se trata, sin embargo, de proteger los dos polos del proceso de socialización, que se expresan a través del lenguaje: los individuos, a los que alude el uso de los pronombres personales, y la red de relaciones sociales, expresadas a través de la trama lingüística y sin cuya potenciación es imposible incluso la individualización, porque sólo a través del reconocimiento recíproco es posible tal proceso. No acierta L. Kohlberg al querer unir, tras las críticas de C. Gilligan, justicia y benevolencia, porque las dos grandes intuiciones morales de nuestra época -la compasión por los individuos vulnerables y el cuidado de las redes sociales a las que deben su identidad y promoción- exigen dos actitudes a las que me he permitido denominar en alguna ocasión las «virtudes del socialismo pragmático»: justicia y solidaridad ${ }^{15}$. La primera cuida de defender las libertades iguales y los derechos iguales de los individuos que se autodeterminan, mientras que la solidaridad -no la benevolencia- se dirige a los componentes de una forma de vida que, al compartiría, se han hermanado ${ }^{16}$. Ninguna de estas dos actitudes

${ }^{14}$ G. H. Mead, Espíritu, persona y sociedad, Buenos Aires, Paidós, 1972 (3. a ed.), 381-390; J. Habermas, «Gerechtigkeit und Solidarität», en W. Edelstein/G. Nunner-Winkler (Hg.), Zur Bestimmung der Moral, Frankfurt, Shurkamp, 1986, 307. De la filosofia habermasiana se han ocupado, entre otros, R. Gabás, J. Habermas: dominio técnico comunidad lingüística, Barcelona, 1980; J. M. Mardones, Razón comunicativa y teoría crítica, Bilbao, Universidad del País Vasco, 1985; E. Menéndez Ureña, La teoría crítica de la sociedad de Habermas, Madrid, Tecnos, 1978; J. Muguerza, «Ética y comunicación (una discusión del pensamiento político de Jürgen Habermas)», en Revista de estudios políticos (Nueva Época), núm. 56 (1987), 7-63. Yo misma le he dedicado buena parte de Crítica y utopía: la escuela de Frankfurt, Madrid, Cincel, 1986.

${ }^{15}$ A. Cortina, «Ética discursiva», en V. Camps (ed.), Historia de la Ética, III, Barcelona, Crítica, en prensa.

${ }^{16}$ En este sentido critica J. Habermas en «Gerechtigkeit und Solidarität» (o. C.) la posición mantenida por L. Kohlberg en el artículo publicado en la 
puede ser descuidada por el socialismo pragmático. Y, sin embargo, permitir a la justicia cumplir su cometido supondría la defensa respetuosa de individuos autónomos, pero ¿cómo entender la autonomía sin tener en cuenta la dimensión subjetiva, en la que concurren intención, móvil, autocoacción, criterio último del juicio?

Realmente el concepto de autonomía, otrora fundamento de lo moral, ha sufrido una transformación puesto que nos remite a la capacidad de todo hablante competente para elevar pretensiones de validez en la praxis comunicativa, mientras que el momento moral se lee en los presupuestos pragmáticos del discurso práctico, así como en el presupuesto contrafáctico, común al discurso teórico y al práctico, de una situación ideal de habla. Pero entonces el fundamento se desplaza hacia el derecho a defender argumentativamente los propios intereses y convicciones y a obtener asimismo de los restantes interlocutores réplicas argumentadas, lo cual permite, a mi juicio, fundamentar una teoría de los derechos humanos que conjugue racionalidad e historia, pero deja a la posible autonomía del sujeto -en este caso de su juicio moral- en una difícil situación. Porque o bien el sujeto debe aceptar como criterio último de lo moralmente correcto lo que decida fácticamente una comunidad real argumentante, o «formación discursiva de la voluntad» significa únicamente utilizar el diálogo con vistas a formar el propio juicio, reservándose la decisión última, o bien el sujeto debe recurrir al hipotético juicio de una comunidad ideal de argumentantes.

En el primer caso se ve obligado a aceptar como moralmente correcto -no como políticamente aceptable o como jurídicamente positivable- lo que fácticamente decida una comunidad de la que no forman parte todos los afectados, que no argumenta en condiciones de simetría ni goza de garantía alguna de que vaya a imponerse la fuerza del mejor argumento. Porque la idea de una comunidad ideal, aunque inserta ya siempre contrafácticamente en la praxis comunicativa, es sólo regulativa en cuanto se trata de fundamentar normas con un ámbito de validez universal, es decir, normas morales en sentido estricto. Por eso los discursos realizados advocatoriamente o internalizados sólo desempeñan una función sustitutiva: las argumentaciones in foro interno no equivalen a los discursos reales que no hayan podido ser llevados a cabo. Esta sería la ventaja de la ética discursiva

misma compilación y escrito en colaboración D. R. Boyd y Ch. Levine: «Die Wiederkehr der sechten Stufe: Gerechtigkeit, Wohlwollen und der Standpunkt der Moral», 205-240. 
frente al monologismo kantiano, y también frente al rawlsiano que, en último término, sólo posibilita una situación ficticia.

Ahora bien, si las condiciones de racionalidad sólo contrafácticamente son presupuestas, ¿cómo formular juicios morales? Parece que hará gala de «buena voluntad» quien esté dispuesto, no sólo a emprender un camino dialogante para resolver conflictos, sino también a aceptar como moralmente correcto el resultado, huyendo del mundo heraclitano de los dormidos, que creen tener inteligencia propia, para ingresar en el de los despiertos, que atienden a lo común. Obviamente, en tal caso la ética discursiva ha de reconocer la falibilidad de todos los conocimientos morales, como reconoce Habermas ${ }^{17}$, y afirmar con caracteres de universalidad y necesidad únicamente las implicaciones morales de los presupuestos pragmáticos de la argumentación, pero la idea de un juicio moral que, no sólo se sabe siempre falible, sino que acepta como criterio de lo correcto lo que una comunidad real esté dispuesta a aceptar como tal ¿respeta la idea de sujeto autónomo?

Si éste no nos parece el modo más adecuado para salvaguardar la autonomía del sujeto, que parece ser misión de la justicia, nos vemos obligados -a mi juicio- a recurrir a uno de los dos caminos restantes. Siguiendo el primero nos introducimos en una «ética del diálogo», del tipo de la que propone Wellmer. Para Wellmer, el mandato de la universalización supone una correcta interpretación de los caracteres relevantes de un caso y exige, por tanto, un diálogo que conduzca al sujeto a esta mejor comprensión; pero ello no significa sustituir el principio de la autonomía de la voluntad por el dialógico, hacer del principio dialógico el principio moral, sino uno de los principios exigidos en el ámbito moral $^{18}$.

Siguiendo el segundo camino más bien ingresamos en un callejón sin salida, porque en realidad apostamos por realizar monológicamente un experimento mental: tratar de concebir cuál sería el juicio moral resultante en el caso de que se celebrara un diálogo en condiciones de racionalidad. Un experimento semejante permite al sujeto mantener una reserva frente a los acuerdos fácticos y continuar defendiendo lo que para él es un juicio que respeta las condiciones de la racionalidad. Pero si éste es el modo de entender la autonomía del juicio, conditio sine qua non del sujeto autónomo, hemos de reconocer que hemos regresado a la universalización monológica, propia de la representación

${ }^{17}$ J. Habermas, «Gerechtigkeit und Solidarität», o. c., 317.

${ }^{18}$ A. Wellmer, Ethik und Dialog, Frankfurt, Suhrkamp, 1986, 48. 
kantiana de un posible reino de los fines. El monologismo, el derecho a defender que el resultado del propio experimento mental constituye lo moralmente correcto, aunque la comunidad fáctica no lo entienda así; la idea de que los demás pueden haber universalizado incorrectamente es entonces la única salida. A mayor abundamiento, y como sugiere A. Wellmer, apelar a una representación semejante supone recurrir a un «absoluto» que Wellmer limita a la pragmática trascendental, pero es -a mi juicio- extensible a la universal: el recurso a una situación ideal supone una interpretación pragmático-lingüística de la filosofía adorniana de la reconciliación, que Adorno pensó como ruptura con la razón existente, porque nos enfrentamos aquí a la imagen de un juicio final. Más que apuntar a una comunión de los santos, la representación de una comunidad ideal sería un trasunto de ese juicio final en que la verdad y la corrección serán definitivamente conocidas, de modo que se haga justicia con todas las pretensiones de validez elevadas en la historia ${ }^{19}$. De nuevo la razón crítica es razón jurídica. ¿Qué tipo de conocimiento moral proporciona esta racionalidad comunicativo-práctica, que te hace superior al «empatismo» kohlbergiano y al «decisionismo» de la «justicia como imparcialidad»?

Ciertamente, la crítica de Habermas a Rawls descansa fundamentalmente en la convicción de que su propuesta contractualista supone un retroceso con respecto a Kant, en cuanto intento de construir un punto de vista moral. El sujeto autónomo kantiano cuenta con un móvil que le brinda la razón práctica misma, en cuanto es efecto de la ley moral en el sentimiento, mientras que las célebres «partes» de la posición original actúan sólo movidos por la prudencia. Por otra parte, desde la perspectiva kantiana quedan satisfechas las pretensiones de cognitivismo moral, en la medida en que el sujeto puede conocer mediante la razón práctica la ley moral, mientras que a las partes rawlsianas sólo pueden exigírseles decisiones racional-teleológicas: no es posible un conocimiento moral que exceda el ámbito de los propios intereses; el conocimiento práctico-moral pertenece al haber del teórico, que ha de explicar por que construye la posición original de un modo determinado ${ }^{20}$.

Realmente esta crítica de «hobbesianismo» dirigida a la propuesta de Rawls y su dificultad de conciliarlo con el presunto

${ }^{19}$ Ibid., 88 ss.

${ }^{20}$ J. Habermas, «Gerechtigkeit und Solidarität», 296-298. Con relación al constructivismo, muy especialmente al rawlsiano, vid. J. Rubio, El hombre y la ética, Barcelona, Anthropos, 1987. 
kantismo del autor no es precisamente nueva, y, sin embargo, puede quedar paliada por los caracteres que la «justicia como imparcialidad» asigna a las personas morales, que no se limitan al velo de la ignorancia y a la racionalidad, sino que se extienden a todo un cuadro formado por dos facultades morales, dos intereses de orden supremo, un interés de orden superior $y$, en relación con la autonomía plena, los dos elementos de toda noción de cooperación social -lo racional y lo razonable ${ }^{21}$. Y si, en definitiva, la formación argumentativa de la voluntad nunca puede llevar a un juicio moral sin reservas, salvo que recurramos al experimento mental, ¿que mayor garantía de conocimiento práctico puede proporcionar la ética discursiva si no es contando con una ficción, aunque esté ya siempre contrafácticamente presupuesta?

Por otra parte, tal vez fuera bueno aprender de la cautela rawlsiana en limitar su «justicia como imparcialidad» a una concepción política de la justicia que, en cuanto tal, es moral, y se aplica particularmente a la estructura básica de una sociedad, en su caso, de una democracia constitucional moderna. Habérselas con una doctrina moral comprehensiva, como es el caso del utilitarismo, no sería el objetivo de la justicia como imparcialidad, porque tal concepción reclamaría una concepción del bien y es ésta una visión de totalidad para la que resulta imposible encontrar un «consenso solapante». Es menester plantearse, pues, el problema de lo correcto antes que el de lo bueno, e incluso restringirlo al ámbito político de la justicia de la estructura básica de la sociedad ${ }^{22}$.

Ciertamente, también la ética discursiva prescinde de lo bueno en el planteamiento de una ética modesta y mínima, pero, sin embargo, no limita su pregunta por lo correcto a la dimensión jurídico-política de una sociedad. Puesto que la naturaleza de la racionalidad comunicativa -que lleva entrañado el telos del

${ }^{21}$ J. Rawls, «Kantiam Constructivism», 528-533.

22 J. Rawls, «Justice as Fairness: Political not Metaphysical» Philosophy and Public Affairs, vol 14, núm. 3 (1985), 224 y 225. La posición de Rawls es defendida también por R. Rorty en el artículo citado en nota 10 y también en «Solidarity or Objectivity?», en J. Rajchman/Cornel West (eds.), Post-Analytic Philosophy, New York, Columbia University Press 1986, 3-19. Para Rorty el contextualismo no sería relativista en la medida en que tampoco defiende ninguna teoría de la verdad, únicamente defiende un etnocentrismo, según el cual sobre la verdad o la racionalidad no puede decirse nada allende las descripciones de justificación de una sociedad determinada en un ámbito determinado de investigación. Naturalmente, la ética discursiva pretende ir más allá del etnocentrismo. 
lenguaje- muestra el carácter dialógico del lógos humano, y puesto que en ella se lee el principio ético, no es la nuestra una concepción de lo correcto aplicada al mundo social, sino la teoría de lo correcto en general. Naturalmente, el proceder rawlsiano es constructivista, mientras que la ética discursiva reconstruye los universales del habla, pero entonces cabe preguntar cuál es el lugar de la legislación moral.

En el contexto kantiano, del que la ética discursiva se piensa la más legítima heredera, tampoco la felicidad o el bien subjetivo era objeto de la ética. Pero las leyes morales no tenían por misión asegurar un ámbito de libertad externa para que cada cual pudiera ser feliz a su manera, porque ésta era misión del derecho. La felicidad es un fin del hombre, no del ciudadano, y entre los principios de la constitución civil cuentan la libertad de ser feliz a su manera y la de no aceptar más ley que aquella a la que he podido dar mi consentimiento $^{23}$. Pero es ésta una legislación que pertenece al mundo jurídico y no al moral. ¿No cabe decir que una «ética mínima» ha asumido las funciones que el formalismo kantiano asignaba al derecho, pero sin sustituir -obviamente- al derecho y gozando, por tanto, de un estatuto ambiguo -por no decir inexistente- en tanto que procedimiento?

Según Habermas, tanto las teorías de la justicia que encarnan el punto de vista moral como el procedimiento jurídico descansan en la idea de que la racionalidad del procedimiento ha de garantizar la validez de los resultados que se obtienen de él; pero a partir de aquí empiezan las diferencias ${ }^{24}$. La primera consiste en reconocer la superioridad del derecho sobre la moral, en cuanto tomamos por canon la racionalidad procedimental: el derecho está ligado a criterios institucionales, independientes, lo cual permite comprobar si la decisión se ha tomado siguiendo la regla, aun sin participar en el procedimiento; mientras que la moral exige reconstruir el punto de vista adoptado y su prueba discursiva, para enjuiciar el procedimiento. Pero también el procedimiento moral se nos presenta como imperfecto en cuanto

\footnotetext{
${ }^{23}$ I. Kant, Gemeinspruch, VIII, 290 y 291; Zum ewigen Frieden, VIII, 349 y 350; Die Metaphysik der Sitten, 314.

${ }^{24}$ De considerarlas más detenidamente me he ocupado en «Límites y virtualidades del procedimiento moral y jurídico», que intenta perfilar los límites de la ética discursiva, prosiguiendo una tarea iniciada en las últimas páginas de Razón comunicativa y responsabilidad solidaria (Salamanca, Sígueme, 1985), de Crítica y utopía, de Ética mínima (Madrid, Tecnos, 1986) y en un reciente trabajo titulado «La reconstrucción de la razón práctica. Más allá del procedimentalismo y el sustancialismo», en Estudios filosóficos, núm. 104 (1988), 165-193.
} 
adolece de insuficiencias cognitivas y emocionales. Insuficiencias cognitivas porque no garantiza infalibilidad, univocidad ni tampoco que el resultado se consiga dentro de un plazo determinado; a mayor abundamiento, la aplicación a las situaciones concretas resulta siempre compleja, puesto que nunca existe certeza de haber destacado las cualidades relevantes de la situación. Pero también la moral adolece de una mayor debilidad motivacional que el derecho, porque la reflexión moral exige poner en cuestión lo que son ya evidencias de nuestras formas de vida.

En este último punto la Moralität, que se alza con la pretensión de construir una brújula para poner en cuestión las evidencias y costumbres del ethos concreto, se encuentra en inferioridad de condiciones con respecto a los defensores de la Sittlichkeit, que han incorporado la moral a las instituciones. Satisfacer el ideal de libertad radical, propio de la modernidad, el afán de universalidad y el afán de revisión y crítica, tiene para la moral «interiorizada» el efecto nocivo de una mayor debilidad motivacional. Pero, a mayor abundamiento, yo diría que esta «moralidad» interiorizada del procedimentalismo se encuentra con el inconveniente, frente a la kantiana, de que ya no le importa la intención, sino «que lo bueno acontezca»y, por otra parte, es impotente para lograr que lo bueno acontezca, dada su imperfección como procedimiento.

$\mathrm{Y}$ es precisamente este cúmulo de debilidades el que exige «complementar» la moral con el derecho positivo, «absorbiendo sus inseguridades» mediante una regulación que puede imponerse coactivamente. Ciertamente una «ética de la responsabilidad», que no de la intención, sólo puede exigir a sus destinatarios el cumplimiento de las normas si existe garantía jurídica de que van a ser cumplidas. Por eso en algún lugar he planteado si la ética discursiva no cae en lo que Apel llama la «paradoja leninista».

Tras apuntar estas deficiencias de la moral, con el fin de mostrar hasta qué punto es necesario complementarla con el derecho positivo, Habermas sigue, sin embargo, presentándonosla como «un procedimiento público que obedece a su propia lógica y que de este modo controla su propia racionalidad» y también como un factor que no se enfrenta al derecho positivo, sino que se establece en él: algo dotado de un carácter procedimental y valioso para la fundamentación de posibles contenidos normativos.

Sin embargo, este procedimiento público, esta argumentación que carece de límites de espacio y tiempo, que en realidad no corre por cauces institucionales, sino que depende de la espontaneidad 
de los componentes de la comunidad real; este diálogo abierto a todos los interlocutores potenciales, pero que en verdad se aproxima a una opinión pública razonante, dirigida sin remedio por los poderes fácticos, ha perdido -a mi juicio- tanto las ventajas de la Moralität como las de la Sittlichkeit. Porque ya no es el reducto último de un sujeto autónomo que, aun sabiéndose persona gracias a un proceso de socialización, se sabe también sujeto de su intención moral y de su juicio, pero tampoco ha encontrado un lugar institucional en un sistema democrático.

Queda, pues, únicamente esa noción «moral» de justicia como imparcialidad, establecida en el seno del derecho positivo y que le presta el halo de inviolabilidad, heredado del derecho sagrado. También la idea de estado de derecho se beneficia de ella y legitima a su vez al derecho fundado -y aplicado, aunque con matizaciones- según la noción de imparcialidad. Y ciertamente los trazos de la razón práctica moderna son los de una legislación imparcial, pero si sólo importan a la libertad externa, tal vez pueda decirse que es todavía el derecho racional el que presta fuerza obligatoria al positivo, aunque ya no resida «sobre él» sino en su interior.

La argumentación moral ha quedado como uno de esos «diálogos edificantes», que sólo pretenden que la conversación no se interrumpa. Tal vez porque no sea tan sencillo reconstruir al sujeto autónomo desde el socialismo pragmático, cuando es un sujeto semejante -y no el individuo ni la comunidad- la condición sin la que no existe el mundo moral. 